\title{
Effects of Sleep Deprivation in Young and Adult Rats: An Assessment of Memory and Anxiety
}

\author{
Parvin Zareian ${ }^{1,{ }^{*}}$ and Mohsen Nategh (i) ${ }^{2}$ \\ ${ }^{1}$ AJA University of Medical Sciences, Tehran, Iran \\ ${ }^{2}$ Neuroscience Research Center, Shahid Beheshti University of Medical Sciences, Tehran, Iran \\ "Corresponding author: AJA University of Medical Sciences, Tehran, Iran. Email: zareianj2011@yahoo.com
}

Received 2020 July 28; Revised 2020 September 09; Accepted 2020 September 09.

\begin{abstract}
As an important issue, sleep deprivation influences the cognition and mood of society. It both causes different effects on various individuals and age groups. However, the effects on various age groups are not well studied. The present study, which used a rat model of sleep deprivation, investigated the learning and memory status of sleep-deprived (SD) rats. Two groups of young and adult rats underwent $96 \mathrm{~h}$ of REM sleep deprivation by the inverted flowerpot method. Control groups were in the same condition but were could sleep normally. In behavioral groups, anxiety was assessed by an elevated plus-maze. Six weeks later, spatial memory was evaluated using the Morris water maze, and fear memory was assessed by passive avoidance learning. Based on the findings, SD increases anxiety in young rats. Regarding the spatial memory, young SD rats showed impairment in retrieval, but adult SD rats failed to learn the task as effectively as the controls. Memory retrieval in the passive avoidance task was impaired only in the adult SD rats. A different stage of memory affected by sleep deprivation in young and adult rats reflected varying mechanisms in these two age groups.
\end{abstract}

Keywords: Sleep Deprivation, Spatial Memory, Avoidance Learning

\section{Background}

Having normal sleeping periods significantly affects the rapid eye movement (REM) and non-REM (NREM) and has an important role in physiologic and cognitive functions (1). Experiments on the total- NREM- and REM-sleep deprivation have shown disturbances in various functions, and several studies have specifically revealed the correlation between REM deprivation and hippocampal plasticity, neurogenesis, and cognitive impairments $(1,2)$. Depending on when sleep deprivation (SD) has occurred, concerning the learning and memory task, SD can influence memory stages of acquisition, consolidation, and retrieval. For example, before learning a task, the SD can impair memory acquisition, while after learning, it causes problems for consolidation (3). Using $72 \mathrm{~h}$ of SD before learning in rats, a study has evaluated cued and contextual fear memory and reported impairment only in the context fear memory task (4). This suggests that SD selectively interferes with hippocampal memory. Further evidence is provided by a report which showed that $96 \mathrm{~h}$ of REM SD impaired the contextual fear memory. However, it was not correlated with glucocorticoid levels (5). The effect of SD on the hip- pocampus in SD rodents is further confirmed by studies that used spatial memory tasks. Mice sleep-deprived for $6 \mathrm{~h}$ after training were failed to discriminate relocated objects $24 \mathrm{~h}$ after the learning session $(6,7)$. Spatial memory assessment using the Morris water maze also confirmed the effects of REM SD on different phases of memory $(8,9)$.

Although SD is widely investigated in various populations of rodents with different ages, few studies have compared SD effects in young and older rats $(10,11)$. A difference in cognitive functions between young and adult rats has raised possible discrepancies in response to the SD.

\section{Objectives}

The present study aimed to investigate the effects of SD on young and adult rats by evaluating memory and anxiety tasks following the REM sleep deprivation.

\section{Methods}

\subsection{Animals}

Male Wistar rats were prepared from the animal lab in the Neuroscience Research center, Shahid Beheshti Univer- 
sity of Medical Sciences. The "young" and "adult" groups consisted of 1 and 14 month-old rats ( 8 rats in each group). There were 4 animals in each cage, and cage-mates were kept together throughout the study. Rats had free access to food and water. Experiments were performed following the recommendations from the Declaration of Helsinki and the internationally accepted principles for the experimental use of rats.

\subsection{REM Sleep Deprivation}

To apply REM deprivation, the flowerpot method was used (12). The Plexiglas box $(60 \times 100 \times 40 \mathrm{~cm})$ consisted of 15 platforms standing $10 \mathrm{~cm}$ above the floor of the box. The tank was filled up to around $9 \mathrm{~cm}$. The box was placed in a quiet room with lights on at $7 \mathrm{AM}$ and off at 7 PM. REM SD started at 5 PM. Rats in the same cages were placed on the platform to avoid social isolation stress. SD was conducted for $96 \mathrm{~h}$, which is a long term SD. For control groups, a wire mesh was fixed on the surface of platforms so that sleeping rats would not contact water upon loss of muscle tone (i.e., occurrence of REM sleep). Experimental groups were assigned as Control and REM-deprived young and adult rats (CYN/RYN and CAN/RAN, respectively). Anxiety studies were done after completion of the SD, but spatial and passive avoidance learning was performed six weeks after completion of SD.

\subsection{Behavioral Testing}

\subsubsection{Elevated Plus Maze}

The elevated plus maze (EPM) was used to assess the anxiety level. The maze had two open and two closed arms. The rats were placed on the center of the maze, and the number of transitions to the open arms and time spent in the open arms was recorded for between-groups comparisons.

\subsubsection{Morris Water Maze Apparatus}

The water maze used in this research was a dark circular pool with a diameter and height of $150 \mathrm{~cm}$ and 60 $\mathrm{cm}$, respectively, which was filled with a water depth of 45 $\mathrm{cm}$. A Plexiglas with $11 \mathrm{~cm}$ diameter, which was adjusted 2 $\mathrm{cm}$ below the water surface, was considered as the escape platform. Swimming was recorded by a CCD camera (Panasonic Inc., Japan), and the locomotion track was followed by a video tracking system for automated analysis of animals' behavior using the Ethovision software (version XT7, Netherlands).

\subsubsection{Assessment of Reference Memory}

To familiarize the animals with the test environment, the day before training, rats were placed in a water tank without a platform to swim for 60 seconds.

The training session consisted of two blocks of 4 trials in a single day. The platform was placed in the center of the fourth quadrant near the north-west labeled direction. Rats had the 60s to swim and find the platform. The recording was stopped either when the rats found the platform or when the time was over. Animals that could not find the platform within the 60 seconds were guided to the platform by the experimenter. 24-hours after the learning session, the probe test was performed. In the interval between learning sessions and the probe test, the platform was removed, and the rats swam for 60 seconds. In the probe test, the rats entered the water, opposite to where the platform was placed. Escape latency traveled distance, velocity, and time spent in the target quadrant were considered for the subsequent analyses.

\subsubsection{Passive Avoidance Learning}

The PA method was used to assess passive avoidance learning. The device consists of two compartments, a bright and a dark compartment, which is connected by a guillotine door. The floor of both compartments is made of stainless steel rods, and the floor of the dark compartment is attached to a shock generator. The rats were placed in the bright compartment, and after $5 \mathrm{sec}$, the door was removed so that the rat could freely move between the two compartments. The habituation trial was repeated $30 \mathrm{~min}$ later. Thirty minutes after the second habituation session, the training trial was performed. In this session, the guillotine door was closed upon the entrance of the rat into the dark compartment, and an electrical shock was applied immediately. The animal remained in the dark compartment for 20 seconds, and then returned to its cage. After two minutes, the animal has left in the bright compartment again, where it stayed for two minutes, this would be regarded as successful learning of the task. If the animal entered the dark compartment within two minutes, a similar electric shock was applied. This process was repeated until the rat would refrain from entering the dark compartment. Twenty-four hours later, the animal was located in the bright compartment for $5 \mathrm{~min}$. Latency to the first entrance (step-through latency, STL) and the time spent in the dark compartment (TDC) was then recorded as criteria of recalling the task.

\subsection{Statistics}

Data are described as mean \pm SEM. To compare rates in the experimental groups, the unpaired student's t-test was 
used. A P value of less than 0.05 was considered statistically significant.

\section{Results}

\subsection{Sleep Deprivation Increased Anxiety in Young Rats}

Anxiety was assessed by an elevated plus-maze right after the end of the SD period. For young rats, there was no difference concerning the number of entries into the open arms between the control and SD groups $\left(t_{11}=1.06, P=0.3\right)$, but the time spent in open arms was significantly lower in $\mathrm{SD}$ rats $\left(\mathrm{t}_{13}=2.27, \mathrm{P}=0.04\right)$ (Figure 1$)$. For adult rats, neither number of entries to the open $\operatorname{arm}\left(\mathrm{t}_{11}=1.03, \mathrm{P}=0.32\right)$ nor the time spent in open arms $\left(t_{11}=0.38, P=0.7\right)$ were different between SD and control rats. Moreover, within-group comparisons were performed for young and adult rats in the control groups. Older rats entered the open arms less frequently than the younger ones $\left(\mathrm{t}_{12}=2.19, \mathrm{P}=0.04\right)$, but time spent in open arms was not different $\left(\mathrm{t}_{12}=1.81, \mathrm{P}=\right.$ 0.09) (Figure 1).

\subsection{Both Young and Adult SD Rats Failed in the Morris Water Maze (MWM) Task}

A Morris water maze test was conducted in three consecutive days of habituation, training, and recall (probe test) in the training sessions. For the young rats and in the training session, time spent in the target quadrant $\left(\mathrm{t}_{13}=\right.$ 2.07, $\mathrm{P}=0.06)$, the Escape latency $\left(\mathrm{t}_{13}=1.06, \mathrm{P}=0.3\right)$, and travelled distance $\left(\mathrm{t}_{13}=1.67, \mathrm{P}=0.11\right)$ were not different between control and SD rats (Figure 2). In the probe session, young SD rats spent less time in the target quadrant compared with the control group $\left(t_{13}=3.68, P=0.002\right)$ (Figure $2)$. There was no difference regarding the escape latency $\left(t_{13}=0.69, P=0.50\right)$. Besides, velocity $\left(t_{13}=2.44, P=0.02\right)$ and travelled distance $\left(t_{13}=2.74, P=0.01\right)$ were both significantly higher in the SD group.

For the adult rats and in the training session, SD and control rats were not different regarding the time spent in the target quadrant $\left(t_{11}=1.89, \mathrm{P}=0.08\right)$. But escape latency was significantly longer in SD rats, which indicates the impaired learning in the $\operatorname{SD}$ group $\left(\mathrm{t}_{11}=2.54, \mathrm{P}=0.02\right)$ (Table 1$)$. Other two parameters, velocity $\left(\mathrm{t}_{11}=1.10, \mathrm{P}=0.29\right)$ and travelled distance $\left(t_{11}=2.18, P=0.051\right)$, remained unchanged. On the probe test, mean values of time spent in the target quadrant $\left(\mathrm{t}_{11}=1.16, \mathrm{P}=0.26\right)$ and escape latency $\left(\mathrm{t}_{11}=1.06, \mathrm{P}\right.$ $=0.3$ ) were decreased and increased, respectively. However, the differences were not significant (Table 1$)$. Velocity $\left(t_{11}=\right.$ $0.74, \mathrm{P}=0.47)$ and travelled distance $\left(\mathrm{t}_{11}=2.10, \mathrm{P}=0.058\right)$ were not significantly different either.

Finally, for the control groups, comparing the young and adult groups revealed no difference in the learning of the spatial task, as time in the target quadrant $\left(t_{12}=1.39\right.$, $\mathrm{P}=0.18)$ and escape latency $\left(\mathrm{t}_{12}=2.08, \mathrm{P}=0.059\right)$ were not different between the groups (Figure 3 ). However, on the probe test, adult rats reached the platform area earlier than the young rats $\left(\mathrm{t}_{12}=2.28, \mathrm{P}=0.04\right)$ but spent similar time in the target quadrant $\left(\mathrm{t}_{12}=0.75, \mathrm{P}=0.46\right)$.

\subsection{Sleep Deprivation Influenced Adult Rats in the Recall of Avoidance Memory}

For further evaluation of learning and memory in the chronic phase of SD, the passive avoidance task was engaged. In the training session, animals were compared based on the number of training trials (that is, receiving electric shock) required for avoiding the dark chamber in the verification trial. However, no significant different was found regarding this parameter between SD and control groups either in young $\left(t_{13}=0.98, P=0.34\right)$ or adult rats $\left(t_{11}\right.$ $=0.97, \mathrm{P}=0.34$ ) (Table 2 ). A day after training, memory retention was assessed and revealed that young SD rats entered the dark chamber with a similar latency compared to the control ones $\left(t_{13}=0.49, P=0.62\right)$. Again, the time spent in the dark chamber was not different between the groups $\left(t_{13}=0.10, P=0.91\right)$. Although adult $S D$ rats showed no change regarding the step-through latency $\left(\mathrm{t}_{11}=0.69, \mathrm{P}\right.$ $=0.50$ ), they stayed in the dark chamber significantly more than control rats $\left(\mathrm{t}_{11}=2.56, \mathrm{P}=0.02\right)$.

Within-group comparison of young and adult controls revealed no difference regarding the step-through latency $\left(t_{12}=0.33, P=0.74\right)$, but time in the dark compartment was significantly lower for adult animals $\left(\mathrm{t}_{12}=2.26, \mathrm{P}=0.043\right)$ (Table 2).

\section{Discussion}

The present study investigated the effects of REM sleep deprivation on learning and memory in two populations of young and adult rats, and it was found that young sleepdeprived rats failed to recall spatial reference memory as effectively as the control group. Adult rats, on the other hand, showed failure in learning the spatial task.

The exact amount of sleep required for the nervous system is not yet clarified, and evidence regarding the impacts of sleep regulations on various functions of the nervous system, including cognition and emotion, are not sufficient (1, 3, 13-15). According to the experiments, total REM or non-REM SD or targeted deprivation have different effects on the nervous system (11). For instance, it has been suggested that REM deprivation reduces neurogenesis, but total SD results in the impaired differentiation of newborn neurons (16). An important consideration in investigations regarding the impacts of SD in young versus 
A

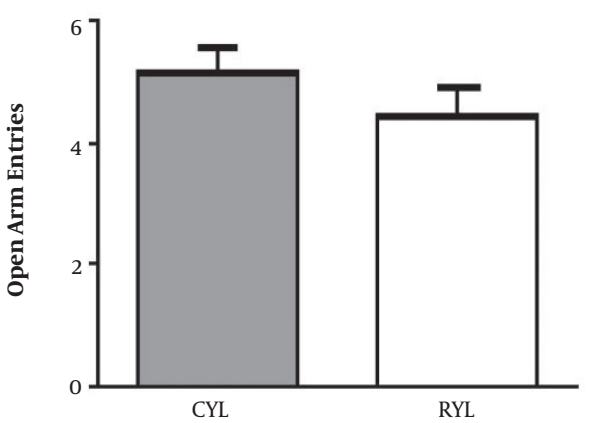

C

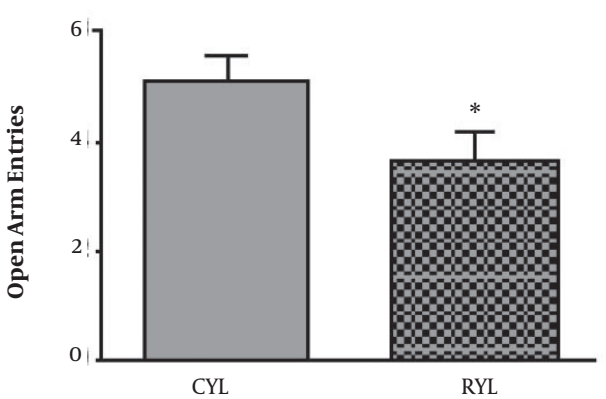

E

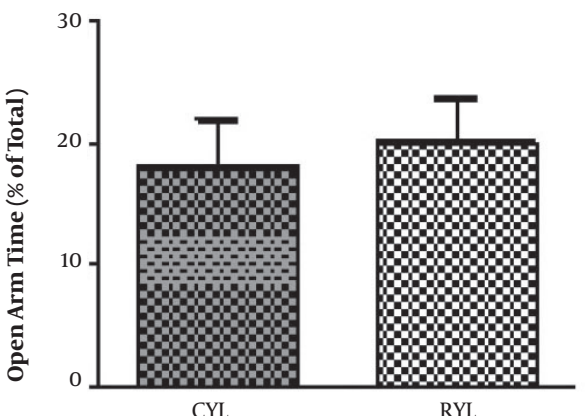

B

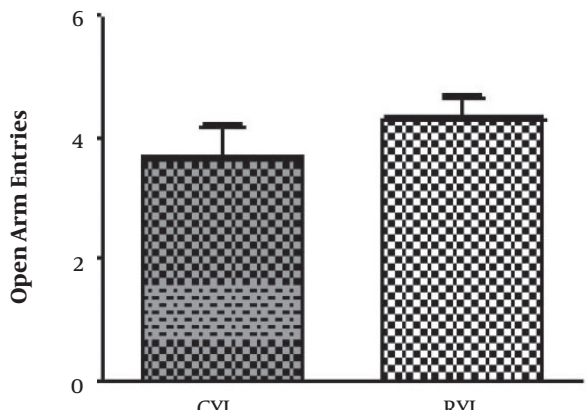

CYL

D

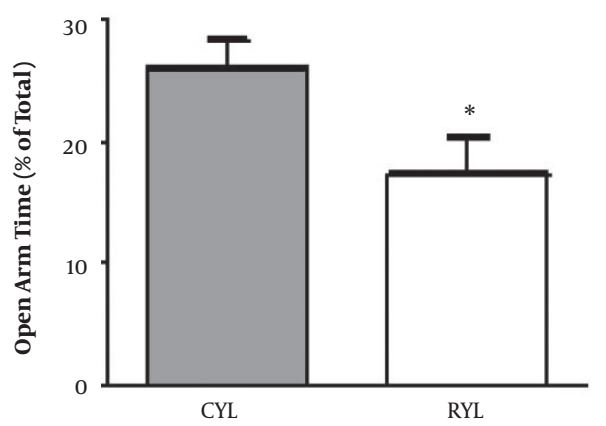

$\mathbf{F}$

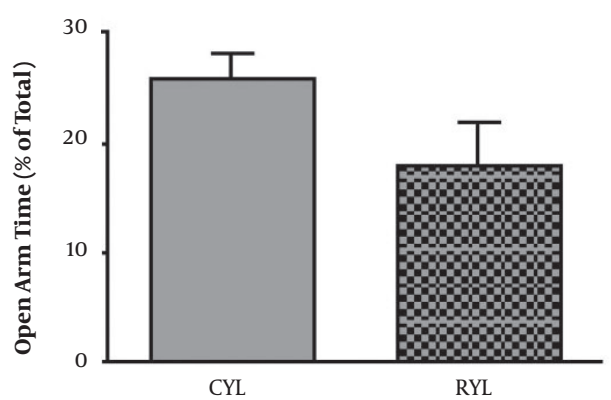

Figure 1. Anxiety assessed by an elevated plus-maze. (A, B, and C) Open arm entry. Time spent in open arms (D, E, and F). CYL, Young control group; CAL, adult control group; RYL, sleep deprivation young group; RAL, sleep deprivation adult group. Data are represented using mean \pm SEM. ${ }^{*}, \mathrm{P}<0.05$.

aged is the well-known fact that in older individuals, sleep tends to be reduced and fragmented (17). This could render young individuals more vulnerable to the impairments in sleep and thus can be used in explaining why some behavioral and histological aspects might remain relatively unaffected in adults compared to young rats.

The elevated plus-maze was used to evaluate anxiety in the acute phase after completion of the SD. Only young SD rats showed a decrease in open arm time, which in- dicates increased anxiety. Meanwhile, adult SD rats did not show increased anxiety. Since Memory tasks in this study were performed in the chronic phase, comparing the anxiety and memory performance would not be reliable. The within-comparison of the control groups revealed that adult rats entered the open arms less frequently than young ones. This suggests higher levels of anxiety in adult rats, but it should be noted that old animals have a lower tendency for locomotion, a condition known as bradykine- 
A

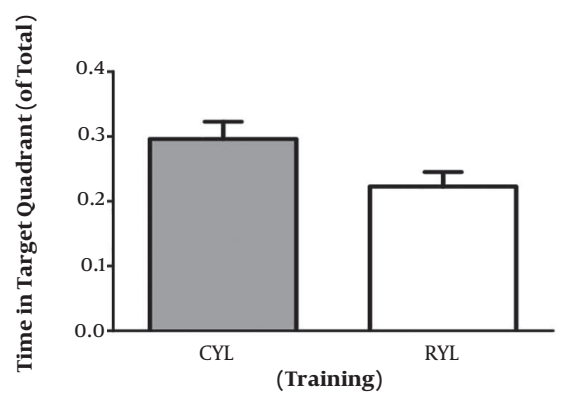

C

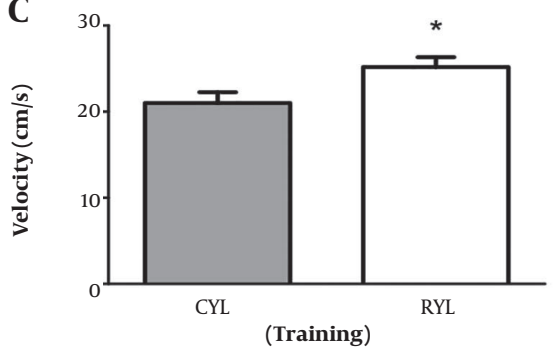

$\mathbf{E}$

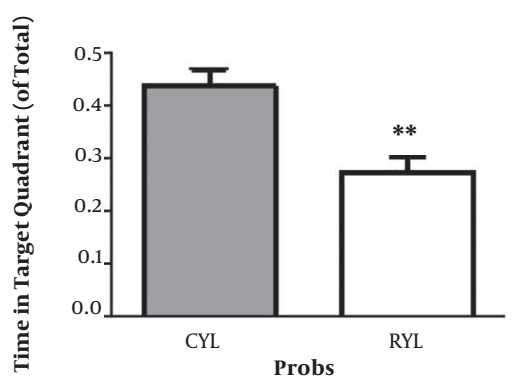

G

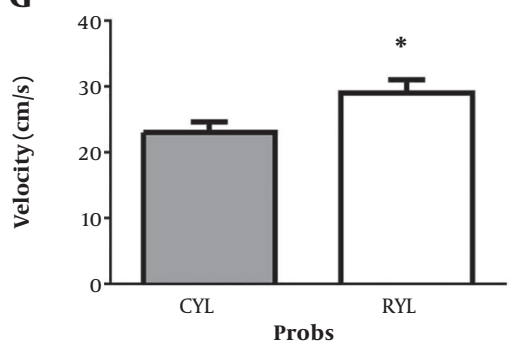

B
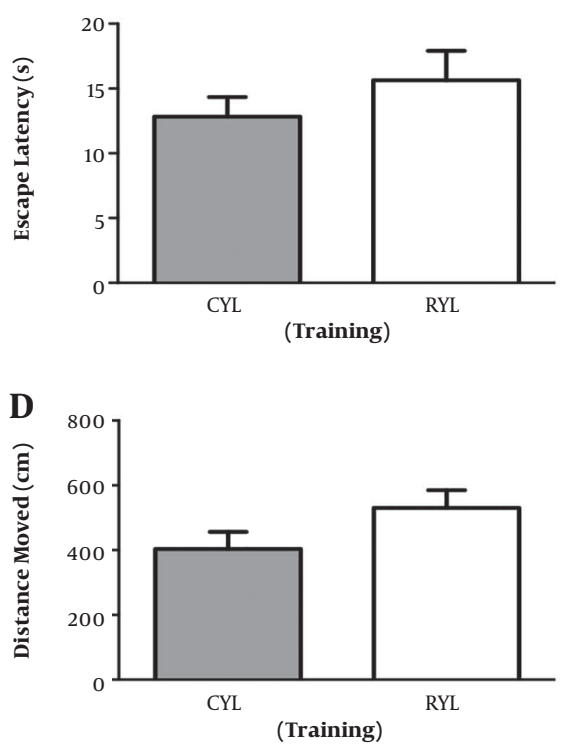

$\mathbf{F}$
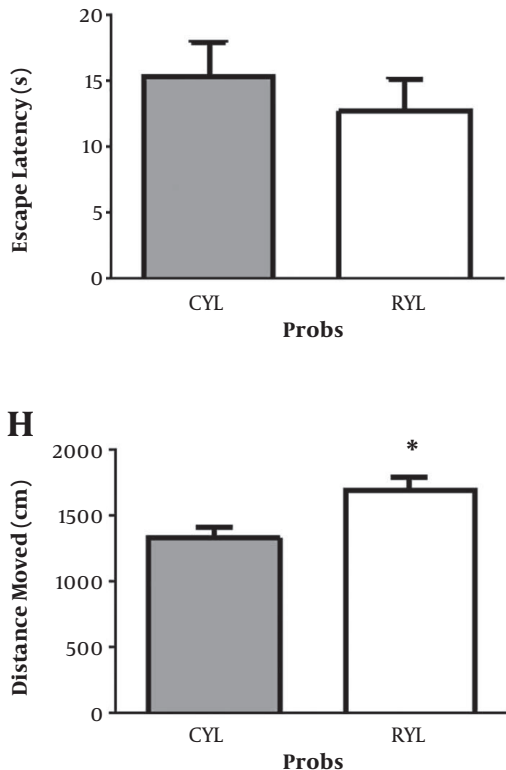

Figure 2. The results MWM test in young rats. Data on the training phase of the MWM test in young rats (A, B, C, and D). Data of probe phase of MWM test in young rats (E, F, G, and H). Data represent mean \pm SEM. ${ }^{*}, \mathrm{P}<0.05,{ }^{* *}, \mathrm{P}<0.01$.

sia in humans (18).

Several studies have mentioned to detrimental effects of SD on learning and memory (5). It appears that the timing of SD with respect to memory assessment has important consequences for the outcome. It's proved that prior to training in a memory task, the SD impairs acquisition, while after training, it interferes with consolidation (1). A spatial working memory task acutely after SD revealed that even 6 - 12 h of SD could disrupt working memory (19). In contrast, in our study, the SD was long-term and well be- 


\begin{tabular}{|c|c|c|c|c|c|}
\hline & Group & Target Quadrant Time, ratio & Escape Latency, s & Velocity, $\mathrm{cm} / \mathrm{s}$ & Distance moved, $\mathrm{cm}$ \\
\hline \multirow[t]{2}{*}{ Training } & CAL & $0.35 \pm 0.02$ & $8.75 \pm 0.99$ & $21.10 \pm 0.78$ & $316.0 \pm 51.54$ \\
\hline & RAL & $0.28 \pm 0.02$ & $14.34 \pm 1.83^{\mathrm{b}}$ & $19.75 \pm 0.90$ & $448.2 \pm 34.57$ \\
\hline \multirow[t]{2}{*}{ Probe } & CAL & $0.41 \pm 0.05$ & $7.47 \pm 1.19$ & $24.84 \pm 0.75$ & $898 \pm 167$ \\
\hline & RAL & $0.34 \pm 0.02$ & $9.53 \pm 1.46$ & $23.60 \pm 1.38$ & $1334 \pm 127$ \\
\hline
\end{tabular}

Abbreviations: CAL, adult control group; CYL, young control group; RAL, sleep deprivation adult group; RYL, sleep deprivation young group.

${ }^{\mathrm{a}}$ Values are expressed as mean \pm SEM.

${ }^{\mathrm{b}} \mathrm{P}<0.05$ compared CAL group.

A

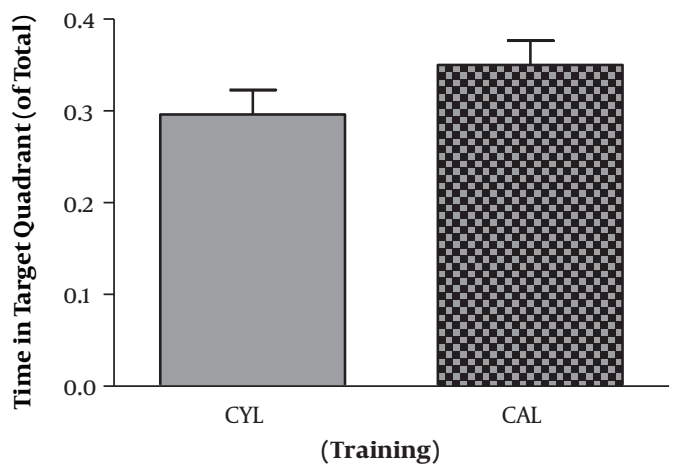

C

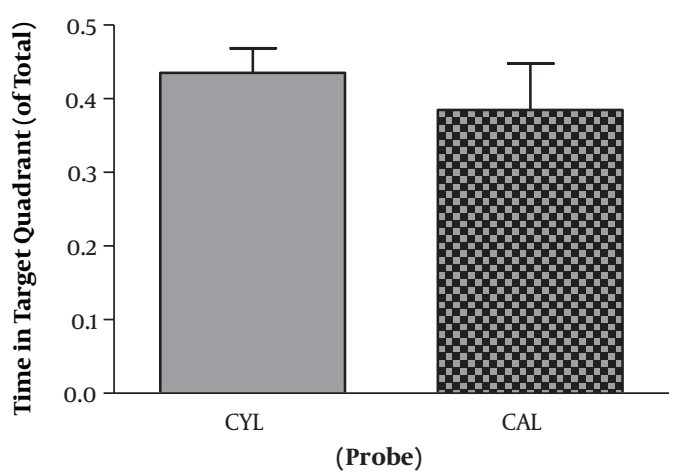

B

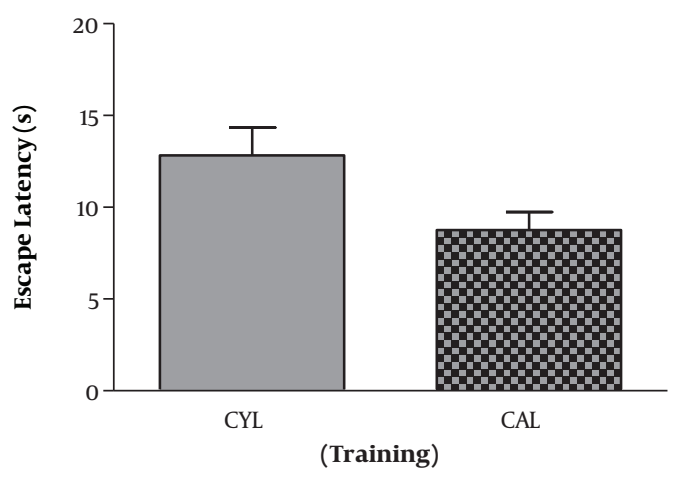

D

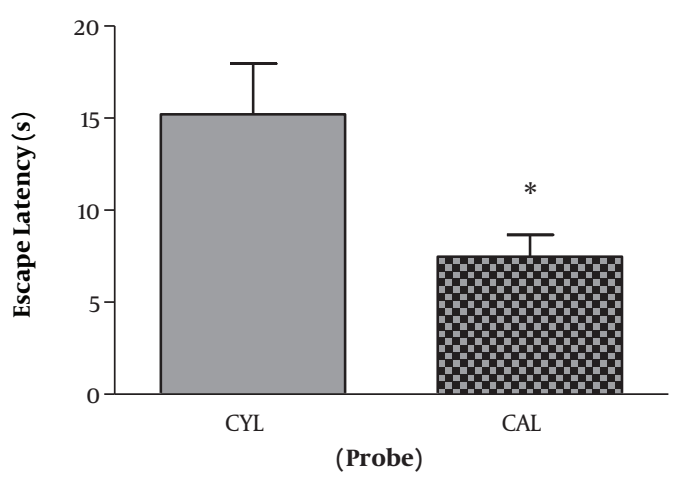

Figure 3. Comparison of young and adult rats in MWM performance. Comparison of young and adult rats in time spent in the target quadrant (A) and escape latency (B) during the training phase. Comparison of young and adult rats in time spent in the target quadrant (C) and escape latency (D) during the probe phase. Data represent mean \pm SEM. ${ }^{*}, \mathrm{P}<0.05$.

fore the learning and memory tasks. When performing an immediate assessment of memory following SD, many factors that play a role in the acute phase can influence memory performance. Since SD tends to influence mainly hippocampal-dependent memory tasks, it can be argued that the hippocampus-specific features, for example, neurogenesis, change in response to $\mathrm{SD}(20)$. In our study, a long-term SD of $96 \mathrm{~h}$ was applied, and learning and memory tests were conducted 6 weeks after the SD. This period was chosen based on the involvement of newborn neurons in the DG circuitry. For a newly proliferated granule cell, it takes around 6 weeks to show functional activity in DG (21). Therefore, neurons that have been proliferated during SD would become functional by the time of memory assessments. As a consequence, if neurogenesis is reduced following SD, DG circuitry could be impaired as well, which can be reflected in DG-related memory functions.

In passive avoidance learning (PAL), the acquisition 


\begin{tabular}{lccc}
\hline \multicolumn{4}{l}{ Table 2. Data of Passive Avoidance Learning in Young and Adult Rats } \\
\hline Group & $\begin{array}{c}\text { Number of Foot } \\
\text { Shocks }\end{array}$ & $\begin{array}{c}\text { Step-Through } \\
\text { Latency, } \mathbf{s}\end{array}$ & $\begin{array}{c}\text { Time in the Dark } \\
\text { Compartment, } \mathbf{s}\end{array}$ \\
\hline CYL & $1.25 \pm 0.16$ & $76.13 \pm 33.93$ & $150.8 \pm 28.87$ \\
\hline RYL & $1.57 \pm 0.29$ & $105.9 \pm 51.12$ & $156.1 \pm 42.73$ \\
\hline CAL & $1.167 \pm 0.16$ & $92.33 \pm 31.35$ & $64.67 \pm 20.74$ \\
\hline RAL & $1.429 \pm 0.20$ & $131.7 \pm 45.01$ & $169.0 \pm 33.00^{*}$ \\
\hline
\end{tabular}

${ }^{\mathrm{a}}$ Values are expressed as mean \pm SEM.

${ }^{\mathrm{b}} \mathrm{P}<0.05$ compared to CAL group.

phase was not affected in either young or adult rats. On the other hand, retrieval was impaired in adult rats. It should be mentioned that PAL is associative learning that involves the hippocampus, though less than MWM (22). It has been shown that SD tends to impair mainly hippocampaldependent tasks $(4,23)$.

In this study, a within comparison of young and adult control groups was performed. Interestingly, adult control rats showed better results regarding the MWM and PAL retrieval phases. On the other hand, their anxiety levels were higher compared to the younger rats. A study reported that mild stress has special beneficial effects on learning and memory of adult rats (24). In a task like MWM, cognitive and physical abilities are important (26). The adult rats in this study were not too aged to show a deficiency in cognitive tasks, yet were physically comparable or even superior to young individuals.

In conclusion, the findings suggest that SD impairs memory consolidation and/or retrieval in young rats, and has negative consequences for the acquisition in the adult rats.

\section{Acknowledgments}

The authors would like to thank Prof. Fereshteh Motamedi for her kind cooperation.

\section{Footnotes}

Authors' Contribution: Parvin Zareian contributed to conception and design to all experimental work, writing of manuscript, and approved the final manuscript. Mohsen Nategh was responsible for data collection and statistical analysis, and interpretation of data. All authors read and approved the final manuscript.

Conflict of Interests: There is no conflict of interest.

Ethical Approval: Experiments were performed following the Declaration of Helsinki and the internationally accepted principles for the experimental use of rats (code: 994628).
Funding/Support: AJA University of Medical Sciences funded this research.

Informed Consent: There was no informed consent.

\section{References}

1. Kreutzmann JC, Havekes R, Abel T, Meerlo P. Sleep deprivation and hippocampal vulnerability: changes in neuronal plasticity, neurogenesis and cognitive function. Neuroscience. 2015;309:173-90. doi: 10.1016/j.neuroscience.2015.04.053. [PubMed: 25937398].

2. Havekes R, Meerlo P, Abel T. Animal studies on the role of sleep in memory: from behavioral performance to molecular mechanisms. Curr Top Behav Neurosci. 2015;25:183-206. doi: 10.1007/7854_2015_369. [PubMed: 25680961].

3. Abel T, Havekes R, Saletin JM, Walker MP. Sleep, plasticity and memory from molecules to whole-brain networks. Curr Biol.2013;23(17):774-88. doi: 10.1016/j.cub.2013.07.025. [PubMed: 24028961]. [PubMed Central: PMC4263505].

4. McDermott CM, LaHoste GJ, Chen C, Musto A, Bazan NG, Magee JC. Sleep deprivation causes behavioral, synaptic, and membrane excitability alterations in hippocampal neurons. J Neurosci. 2003;23(29):9687-95. [PubMed: 14573548].

5. Tiba PA, Oliveira MG, Rossi VC, Tufik S, Suchecki D. Glucocorticoids are not responsible for paradoxical sleep deprivation-induced memory impairments. Sleep. 2008;31(4):505-15. [PubMed: 18457238]. [PubMed Central: PMC2279753].

6. Florian C, Vecsey CG, Halassa MM, Haydon PG, Abel T. Astrocytederived adenosine and A1 receptor activity contribute to sleep lossinduced deficits in hippocampal synaptic plasticity and memory in mice. J Neurosci. 2011;31(19):6956-62. doi: 10.1523/JNEUROSCI.576110.2011. [PubMed: 21562257]. [PubMed Central: PMC3140051].

7. Havekes R, Bruinenberg VM, Tudor JC, Ferri SL, Baumann A, Meerlo $P$, et al. Transiently increasing cAMP levels selectively in hippocampal excitatory neurons during sleep deprivation prevents memory deficits caused by sleep loss. J Neurosci. 2014;34(47):15715-21. doi: 10.1523/JNEUROSCI.2403-14.2014. [PubMed: 25411499]. [PubMed Central: PMC4236401].

8. Li S, Tian Y, Ding Y, Jin X, Yan C, Shen X. The effects of rapid eye movement sleep deprivation and recovery on spatial reference memory of young rats. Learn Behav. 2009;37(3):246-53. doi: 10.3758/LB.37.3.246. [PubMed: 19542091].

9. Yang RH, Hu SJ, Wang Y, Zhang WB, Luo WJ, Chen JY. Paradoxical sleep deprivation impairs spatial learning and affects membrane excitability and mitochondrial protein in the hippocampus. Brain Res. 2008;1230:224-32. doi: 10.1016/j.brainres.2008.07.033. [PubMed: 18674519].

10. Acosta-Pena E, Camacho-Abrego I, Melgarejo-Gutierrez M, Flores G, Drucker-Colin R, Garcia-Garcia F. Sleep deprivation induces differential morphological changes in the hippocampus and prefrontal cortex in young and old rats. Synapse. 2015;69(1):15-25. doi: 10.1002/syn.21779. [PubMed: 25179486].

11. Fernandes C, Rocha NB, Rocha S, Herrera-Solis A, Salas-Pacheco J, Garcia-Garcia F, et al. Detrimental role of prolonged sleep deprivation on adult neurogenesis. Front Cell Neurosci. 2015;9:140. doi: 10.3389/fncel.2015.00140. [PubMed: 25926773]. [PubMed Central: PMC4396387].

12. Youngblood BD, Zhou J, Smagin GN, Ryan DH, Harris RB. Sleep deprivation by the "flower pot" technique and spatial reference memory. Physiol Behav. 1997;61(2):249-56. doi: 10.1016/s0031-9384(96)00363-0. [PubMed: 9035255].

13. Diekelmann S, Born J. The memory function of sleep. Nat Rev Neurosci. 2010;11(2):114-26. doi: 10.1038/nrn2762. [PubMed: 20046194]. 
14. Walker MP, Stickgold R. Sleep-dependent learning and memory consolidation. Neuron. 2004;44(1):121-33. doi: 10.1016/j.neuron.2004.08.031. [PubMed: 15450165].

15. Walker MP. Sleep-dependent memory processing. Harv Rev Psychiatry. 2008;16(5):287-98. doi: 10.1080/10673220802432517. [PubMed: 18803104].

16. Shiromani PJ, Lu J, Wagner D, Thakkar J, Greco MA, Basheer R, et al. Compensatory sleep response to $12 \mathrm{~h}$ wakefulness in young and old rats. Am J Physiol Regul Integr Comp Physiol. 2000;278(1):R125-33. doi: 10.1152/ajpregu.2000.278.1.R125. [PubMed: 10644630].

17. Segovia G, del Arco A, Mora F. Environmental enrichment, prefrontal cortex, stress, and aging of the brain. J Neural Transm (Vienna).2009;116(8):1007-16. doi:10.1007/s00702-009-0214-0. [PubMed: 19343473].

18. Hagewoud R, Havekes R, Novati A, Keijser JN, Van der Zee EA, Meerlo P. Sleep deprivation impairs spatial working memory and reduces hippocampal AMPA receptor phosphorylation. J Sleep Res. 2010;19(2):280-8. doi: 10.1111/j.1365-2869.2009.00799.x. [PubMed: 20050994].

19. Guzman-Marin R, Suntsova N, Bashir T, Nienhuis R, Szymusiak R McGinty D. Rapid eye movement sleep deprivation contributes to re- duction of neurogenesis in the hippocampal dentate gyrus of the adult rat. Sleep. 2008;31(2):167-75. [PubMed: 18274263]. [PubMed Central: PMC2225569].

20. Deng W, Aimone JB, Gage FH. New neurons and new memories: how does adult hippocampal neurogenesis affect learning and memory? Nat Rev Neurosci. 2010;11(5):339-50. doi: 10.1038/nrn2822. [PubMed: 20354534]. [PubMed Central: PMC2886712].

21. Patti CL, Zanin KA, Sanday L, Kameda SR, Fernandes-Santos L, Fernandes HA, et al. Effects of sleep deprivation on memory in mice: role of state-dependent learning. Sleep. 2010;33(12):1669-79. [PubMed 21120129]. [PubMed Central: PMC2982737].

22. Ruskin DN, Lahoste GJ. Aspects of learned fear related to the hippocampus are sleep-dependent. Behav Brain Res. 2008;191(1):67-71. doi: 10.1016/j.bbr.2008.03.011. [PubMed: 18423642].

23. Adlard PA, Engesser-Cesar C, Cotman CW. Mild stress facilitates learning and exercise improves retention in aged mice. Exp Gerontol. 2011;46(1):53-9. doi: 10.1016/j.exger.2010.10.001. [PubMed: 20951791].

24. D'Hooge R, De Deyn PP. Applications of the Morris water maze in the study of learning and memory. Brain Res Brain Res Rev. 2001;36(1):6090. [PubMed: 11516773]. 